\title{
CFD Friction Factors Verification in an Underground Mine
}

\author{
Marc Bascompta $^{1}$, Jordi Vives ${ }^{2}$, Lluís Sanmiquel ${ }^{1}$, José Juan de Felipe ${ }^{2}$ \\ ${ }^{1}$ ICL Chair in Sustainable Mining, Polytechnic University of Catalonia (UPC) \\ Avenue Bases de Manresa, 61-73, 08242-Manresa, Barcelona, Spain \\ marc.bascompta@upc.edu; 1luis.sanmiquel@upc.edu \\ ${ }^{2}$ Department of Mining Engineering, Industrial and ICT, Polytechnic University of Catalonia (UPC) \\ Avenue Bases de Manresa, 61-73, 08242-Manresa, Barcelona, Spain \\ jordi.vives@upc.edu; jose.juan.de.felipe@upc.edu
}

\section{Extended Abstract}

Friction factor determination is necessary to model the ventilation system in an underground mine. These parameters were obtained by means of in situ measurements in two potash mines between 2013-2015 [1-2], obtaining an adjusted model to the reality in terms of airflow distribution. In this study, the friction factors were verified by means of a CFD software. The simulation of the air behaviour inside the mine drifts was done using a multiphysical numerical model of computational fluid dynamics (CFD). The well-known FLOW-3D® software was applied to numerically solve NavierStokes equations for solution domains, introducing deviations and mean values of airflow and cross-sections. A standard $\mathrm{k}$-Ypsilon model was used to estimate turbulence flow. These models are based on the fluid volume method and are capable of simulating ventilation flow conditions. Results obtained by this method displayed similar friction factors to the values obtained from in situ measurements.

Keywords: CFD, Mine Ventilation, Friction Factor.

\section{References}

[1] M. Bascompta Massanés, L. Sanmiquel Pera, and J. Oliva Moncunill, "Determination of the friction factors in potash mines," Journal of Mining Science, vol. 50, no. 5, pp. 953-958, 2014.

[2] M. Bascompta Massanés, Ll. Sanmiquel Pera, H. F. Anticoi Sudzuki, "Friction factors determination and comparison in potash mines," Spain Minergy Congress, 2015. 